\title{
Dispersive Micro-solid Phase Extraction Coupled With Dispersive Liquid-liquid Microextraction for Speciation of Antimony in Environmental Water Samples by Electrothermal Vaporization ICP-MS
}

\author{
Shizhong Chen*, Shengping Zhu, and Dengbo Lu \\ College of Food Science and Engineering, Wuhan Polytechnic University, \\ Wuhan 430023, P.R. China
}

\section{INTRODUCTION}

It is well known that antimony (Sb) is a ubiquitous and cumulative toxic element. It may cause a wide variety of adverse health effects, including respiratory tract irritation, dermatitis, and suppuration of the nasal septum, gastritis, and cellular damage in the lungs $(1,2)$. In particular, the physicochemical and toxic properties of Sb strongly depend on its chemical forms. The inorganic species of $\mathrm{Sb}$ are more toxic than its organic ones (3). The toxicity of $\mathrm{Sb}$ (III) is 10 times higher than that of $\mathrm{Sb}(\mathrm{V})(4,5)$. Therefore, it is necessary not only to determine total $\mathrm{Sb}$, but also to determine $\mathrm{Sb}$ speciation in real samples to evaluate its human health risk.

The problems of $\mathrm{Sb}$ speciation analysis in environmental samples lie in its low concentration level and the complex matrix interference. Therefore, a separation and pre-concentration technique for the different species is usually required prior to their determination. As a classical sample pretreatment technique, solid phase extraction (SPE) has been used widely for an element and its speciation analysis (6-8). However, this technique suffers from certain shortcomings such as solvent loss, large secondary waste, and a long procedure (9, 11). To overcome these problems, a new method named dispersive micro-solid phase extraction (DMSPE) has received increasing attention in the analytical sciences

\footnotetext{
*Corresponding author.

E-mail: chensbizbong62@163.com

Tel: +862783956442
}

\section{ABSTRACT}

A new method based on the dispersive micro-solid phase extraction (DMSPE) and dispersive liquid-liquid microextraction (DLLME) is described for the speciation of inorganic antimony $\mathrm{Sb}$ by electrothermal vaporization inductively coupled plasma mass spectrometry (ETV-ICP-MS) In DMSPE, titanium dioxide nanofibers were used as an adsorbent for the preconcentration and separation of the analytes. The upper aqueous phase and elution solution from DMSPE were used for further preconcentration and separation of $\mathrm{Sb}$ (III) and $\mathrm{Sb}(\mathrm{V})$ by DLLME without any pre-oxidation or pre-reduction operation, respectively. The extracts from DLLME were used for ETV-ICP-MS determination. The main factors affecting DMSPE and DLLME were examined in detail. Under the optimal conditions, the detection limits of this method were 0.025 and $0.041 \mathrm{pg} \mathrm{mL}^{-1}$ with relative standard deviations of $6.3 \%$ and $5.4 \%$ for $\mathrm{Sb}$ (III) and $\mathrm{Sb}(\mathrm{V})(\mathrm{c}=1.0$ $\mathrm{ng} \mathrm{mL}^{-1}, \mathrm{n}=9$ ), respectively. This method was successfully applied for the analysis of Sb speciation in environmental water samples. A certified reference material of water sample was analyzed by this method, and the results of total $\mathrm{Sb}$ obtained were in agreement with the certified values.

owing to its major advantages of simple operation, short extraction time, high extraction efficiency, less adsorbent consumption, and bulk solution extraction (10-12). It is worth noting that an adsorbent material plays a crucial role in DMSPE (13). Various substances have been developed for DMSPE adsorbents (11, 12-16). Titanium dioxide nanofibers (TDNFs) possess some unique properties such as large specific surface area, high chemical stability, corrosion-resistance, non-toxicity and low cost, which make them a promising candidate as adsorbers. However, the study on TDNFs as a solid phase extraction adsorbent for elemental speciation has received little attention (17).

In recent years, a series of liquid phase microextraction (LPME) procedures have emerged in the analytical sciences, including singledrop microextraction, hollow fiber liquid phase microextraction, dispersive liquid-liquid microextraction (DLLME), cloud point extraction, continuous-flow microextraction, and solidified floating organic drop microextraction (18-24). Despite the many benefits of LPME such as simplicity, low cost, rapid phase transfer and high enrichment factor (EF), its application is considerably limited because of the complex or "dirty" sample matrix. Thus, the majority of works by LPME in the literature are focused on the analysis of elemental speciation in water samples with simple matrices (25). It should be pointed out here that each technique has its advantages and disadvantages. Recently, some investigations showed that an important strategy is the coupling of different pretreatment techniques for the determination of the analytes at an extremely low concentration level in real samples (26-31). To the best of our 
knowledge, the use of DMSPE coupled with DLLME for Sb speciation has never been reported in the literature.

Inductively coupled plasma mass spectrometry (ICP-MS) has been proven to be one of the most powerful analysis tools for elements and their speciation due to its merits of high sensitivity, wide linear dynamic range, and rapid multielement detection capability (32-38). However, a liquid nebulization sample introduction procedure for conventional ICP-MS is not compatible with LPME because of its large sample consumption. For these reasons, the application of LPME for elements and their speciation has been done by AAS in most cases (39). Electrothermal vaporization (ETV), as a sample introduction device for ICP-MS, has the advantages of high introduction efficiency, low absolute detection limits, and partial or complete removal of the organic/inorganic solvent/matrix (40-42). Moreover, the microamount of sample requirement with ETV matches that of LPME well. In addition, the use of a chemical modifier in ETV, especially an organic chelating reagent, could change refractory elements to their volatile species and greatly improve the analytical performance of ETV-ICP-MS (43-45).

In this work, a novel method based on DMSPE and DLLME was developed for the Sb speciation by ETV-ICP-MS. In DMSPE, TDNFs were used as an adsorbent for the concentration and separation of the analytes. The upper aqueous phase and elution solution from DMSPE were used for further preconcentration and separation of $\mathrm{Sb}$ (III) and $\mathrm{Sb}(\mathrm{V})$ by DLLME without any preoxidation or pre-reduction operation, respectively. In DLLME, ammonium pyrroinedithiocarbamate (APDC) and $\mathrm{CHCl}_{3}$ were used as a chelating reagent and as an extraction solvent, respectively.
The extracts from DLLME were used for ETV-ICP-MS determination with APDC as a chemical modifier. This method was applied successfully for the analysis of $\mathrm{Sb}$ speciation in environmental water samples.

\section{EXPERIMENTAL}

\section{Instrumentation}

A Series-7 ICP-MS system (Thermo Fisher Scientific Corporation, USA), equipped with a modified commercially available WF-4C graphite furnace (Beijing Second Optics, P.R. China) as the electrothermal vaporizer, was used for the determination of the analytes. The operating parameters of the ICP-MS were optimized with a concentric glass nebulizer prior to connection with the ETV device. A pyrolytic graphite tube was used throughout this work. The working conditions of ETV-ICP-MS are summarized in
Table I. The $\mathrm{pH}$ value of the solution was controlled with a $\mathrm{pH}$ meter (Thermo Orion Corporation, USA) supplied with a combined electrode. An Ethos T microwave digestion device (Milestone, Italy) was used for sample digestion. A KQ-50E ultrasonic bath (Kunshan Ultrasonic Instrument Co., Ltd., Suzhou, P.R. China) was used for obtaining fine droplets. A TG16-WS centrifuge (Hunan Xiangyi Centrifuge Instrument Co., Ltd., Changsha, P.R. China) was used to accelerate phase separation.

\section{Reagents and Solutions}

Unless otherwise stated, all reagents were of high purity or at least of analytical grade. The stock standard solutions of $1.0 \mathrm{mg} \mathrm{mL}^{-1}$ $\mathrm{Sb}(\mathrm{III})$ and $1.0 \mathrm{mg} \mathrm{mL}^{-1} \mathrm{Sb}(\mathrm{V})$ were prepared by dissolving appropriate amounts of $\mathrm{K}(\mathrm{SbO}) \mathrm{C}_{4} \mathrm{H}_{4} \mathrm{O}_{6}$ (Tianjin Reagent Factory, P.R. China) and $\mathrm{K}_{2} \mathrm{H}_{2} \mathrm{Sb}_{2} \mathrm{O}_{7}$ (Shanghai Reagent Fac-

TABLE I

Instrumental Operating Parameters for ETV-ICP-MS

\begin{tabular}{ll}
\hline ICP-MS Plasma Conditions & \\
\hline Plasma Power & $1300 \mathrm{~W}$ \\
Plasma Argon Flow Rate & $14.5 \mathrm{~L} \mathrm{~min}^{-1}$ \\
Auxiliary Argon Flow Rate & $0.91 \mathrm{~L} \mathrm{~min}{ }^{-1}$ \\
Nebulizer Argon Flow Rate & $0.95 \mathrm{~L} \mathrm{~min}{ }^{-1}$ \\
Sampler Orifice (nickel) & $1.1 \mathrm{~mm}$ \\
Skimmer Orifice (nickel) & $0.7 \mathrm{~mm}$ \\
Acquisition Mode & Peak-jumping \\
Number of Sweep & 100 \\
Dwell Time & $10 \mathrm{~ms}$ \\
Acquisition Time & $40 \mathrm{~s}$ \\
Number of Measurements per Peak & 3 \\
Isotopes & $121 \mathrm{Sb}$ \\
\hline ETV Conditions & \\
\hline Sample Volume & $10 \mu \mathrm{L}$ \\
Carrier Gas Flow Rate & $0.45 \mathrm{~L} \mathrm{~min}{ }^{-1}$ \\
Drying Step & $100{ }^{\circ} \mathrm{C}$, ramp10 s, hold $10 \mathrm{~s}$ \\
Ashing Step & $200{ }^{\circ} \mathrm{C}$, ramp10 s, hold $20 \mathrm{~s}$ \\
Vaporization Step & $2000{ }^{\circ} \mathrm{C}$, hold $4 \mathrm{~s}$ \\
Clear-out Temperature & $2600{ }^{\circ} \mathrm{C}$ \\
\hline
\end{tabular}




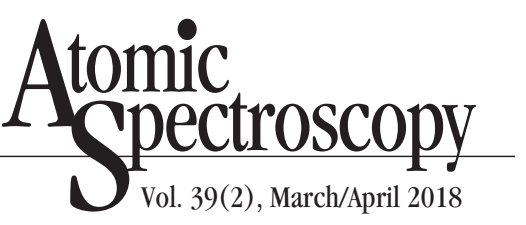

tory, P.R. China) in high purity deionized water, respectively. The working solutions were prepared daily by appropriate dilution of the stock solutions. The APDC solution was prepared by dissolving proper amounts of APDC (Shanghai Reagent Factory, P.R. China) in high purity water. Chlorobenzene, carbon tetrachloride, 1,2-dichloroethane, chloroform, acetonitrile, acetone, ethanol, and methanol were purchased from Shanghai Reagent Factory (Shanghai, P.R. China). High purity deionized water obtained from a Milli-Q ${ }^{\circledR}$ A10 system (Millipore Corporation, USA) was used throughout this work. All glass and polypropylene wares were kept in $2.0 \mathrm{~mol} \mathrm{~L}^{-1} \mathrm{HNO}_{3}$ solution for at least one night, then rinsed with $0.1 \mathrm{~mol} \mathrm{~L}^{-1} \mathrm{HNO}_{3}$ solution, and subsequently with deionized water before use. TDNFs were fabricated by a facile electrospinning and subsequent annealing method, and the diameter of the TDNFs was mainly in the range of $350-450 \mathrm{~nm}$.

\section{Sample Pretreatment}

The water samples (Wuhan, P.R. China) were collected in 50-mL polyethylene containers, then filtered through a $0.45-\mu \mathrm{m}$ membrane filter, and stored in polyethylene bottles at $4{ }^{\circ} \mathrm{C}$ for future use. The storage period was kept as short as possible. The blanks were prepared exactly as the samples except that no analytes were added.

\section{Dispersive Micro-solid Phase Extraction}

A 5.0-mL sample solution $(\mathrm{pH}=5.0)$ spiked with the target analytes was placed in a $10-\mathrm{mL}$ screw cap test tube with a conic bottom. A 6.0-mg amount of TDNFs was added to the test tube, followed by sonication for 6 seconds. After extraction, the mixture was centrifuged at $6000 \mathrm{rpm}$ for 5 minutes to separate the TDNFs from the aqueous solution. The upper aque- ous phase containing $\mathrm{Sb}(\mathrm{III})$ was carefully removed into a $10-\mathrm{mL}$ centrifuge tube. The $\mathrm{Sb}(\mathrm{V})$ retained on the TDNFs was desorbed with 2.0 $\mathrm{mL}$ of $0.5 \mathrm{~mol} \mathrm{~L}^{-1} \mathrm{HNO}_{3}$ by vortex for 2 minutes. The obtained desorption solution was transferred into another 10-mL centrifuge tube.

\section{Dispersive Liquid-liquid Microextraction}

Two aliquots of $100 \mu \mathrm{L}$ APDC (as chelating reagent) solution were added into the upper aqueous phase $(\mathrm{pH}=5.0)$ containing $\mathrm{Sb}(\mathrm{III})$ and the desorption solution $(\mathrm{pH}=0.5)$ containing $\mathrm{Sb}(\mathrm{V})$, respectively, then calibrated to $5.0 \mathrm{~mL}$. The two solutions were shaken for 1 minute and sonicated for 2 minutes to mix the sample solutions and to promote the formation of the APDC-Sb(III) and APDC-Sb(V) complexes. Then, the two aliquots of $0.2 \mathrm{~mL}$ ethanol (as dispersive solvent) containing $15 \mu \mathrm{L} \mathrm{CHCl}_{3}$ (as extraction solvent) were added to the aforementioned solutions, respectively, and cloudy solutions formed immediately. Phase separation was achieved by centrifugation at $5000 \mathrm{rpm}$ for 3 minutes. After the end of the centrifugation cycle, a small droplet of $\mathrm{CHCl}_{3}$ containing the analtyes was sedimented at the bottom of the conical test tube. Finally, an amount of $10 \mu \mathrm{L}$ of the sedimented phase was injected into the ETV device for ICP-MS analysis.

\section{ETV-ICP-MS Procedure}

After the ETV unit was connected to the ICP-MS, $10 \mu \mathrm{L}$ of the analytes in the organic solvent was injected into the graphite furnace. During the drying step, the dosing hole of the graphite furnace was kept open to remove the water and the organic vapor. Then, it was sealed with a graphite probe within 5-10 seconds before the vaporization step. The vaporized analytes were swept into the plasma excitation source by a carrier gas, and the peak-hop transient mode for data acquisition was used for the determination of the analytes.

\section{RESULTS AND DISCUSSION}

\section{Optimization of DMSPE Parameter}

\section{Effect of $p H$}

The $\mathrm{pH}$ of the sample solution plays a key role in speciation separation and adsorption efficiency. It proved to be a primary parameter in the following experiments. Therefore, the effect of sample $\mathrm{pH}$ on the adsorption of the analytes on the TDNFs was investigated in the $\mathrm{pH}$ range of 1.0-8.0. The results in Figure 1 show that in the $\mathrm{pH}$ range of 3.0-6.0, $\mathrm{Sb}(\mathrm{V})$ was retained on the TDNFs with an adsorption percentage above $90 \%$, while $\mathrm{Sb}$ (III) was not retained on the TDNFs in the tested $\mathrm{pH}$ range. This fact reveals that $\mathrm{Sb}(\mathrm{V})$ could be effectively separated from $\mathrm{Sb}$ (III) on the TDNFs by selection of a proper $\mathrm{pH}$. In this work, a $\mathrm{pH}$ of 5.0 was selected for the separation of $\mathrm{Sb}(\mathrm{V})$ and $\mathrm{Sb}(\mathrm{III})$.

The adsorption behaviors of $\mathrm{Sb}(\mathrm{V})$ and $\mathrm{Sb}(\mathrm{III})$ on the TDNFs may be explained in terms of the surface charge of the TDNFs (46). When the $\mathrm{pH}$ is in the range of 3.0-6.0, $\mathrm{Sb}$ (III) mainly exists as $\mathrm{H}_{3} \mathrm{SbO}_{3}$ and $\mathrm{Sb}(\mathrm{OH})_{3}$, while $\mathrm{Sb}(\mathrm{V})$ exists predominantly as $\mathrm{H}_{2} \mathrm{SbO}_{4}^{-}$and $\mathrm{Sb}(\mathrm{OH})_{6}{ }^{-}$. At an acidic condition, the surface of the TDNFs is electropositive $\left(\mathrm{TiOH}_{2}{ }^{+}\right)$which favors the adsorption of $\mathrm{H}_{2} \mathrm{SbO}_{4}^{-}$and $\mathrm{Sb}(\mathrm{OH})_{6}^{-}$.

In addition, the adsorption capacity was investigated by the method recommended in the literature (47). In the particle size range of 350-450 nm, the adsorption capacity of $\mathrm{Sb}(\mathrm{V})$ on the TDNFs was $3.1 \mathrm{mg} \mathrm{g}^{-1}$.

\section{Effect of Adsorbent Amount}

To obtain an optimum TDNF dosage necessary for the separation and preconcentration of the ana- 
lytes, the amount of TDNFs was varied from 1.0 to $10 \mathrm{mg}$ per sample solution $(5.0 \mathrm{~mL})$. It was found that the quantitative adsorption of $\mathrm{Sb}(\mathrm{V})$ was achieved with amounts ranging from $5.0-10 \mathrm{mg}$. Thus, a 6.0-mg amount of TDNFs was used for further experiments.

\section{Effect of Concentration and Volume of Eluent}

Due to the low adsorption efficiency of $\mathrm{Sb}(\mathrm{V})$ at $\mathrm{pH}<2.0$, the diluted $\mathrm{HNO}_{3}$ solution was employed for the fast and quantitative elution of $\mathrm{Sb}(\mathrm{V})$ retained on the TDNFs by vortex. The effect of $\mathrm{HNO}_{3}$ concentration on the recovery of $\mathrm{Sb}(\mathrm{V})$ was studied in its concentration range of $0.1-1.5 \mathrm{~mol} \mathrm{~mL}^{-1}$. The experimental results show that the retained $\mathrm{Sb}(\mathrm{V})$ could be eluted quantitatively with a $0.5-\mathrm{mol} \mathrm{L}^{-1}$ $\mathrm{HNO}_{3}$ solution. Furthermore, the effect of eluent volume on the recovery of the analytes was also studied with a $0.5-\mathrm{mol} \mathrm{L}^{-1} \mathrm{HNO}_{3}$ solution. The experimental results indicated that quantitative recoveries (>90.0\%) could be ob-tained with $2.0 \mathrm{~mL}$ of a $0.5-\mathrm{mol} \mathrm{L}^{-1} \mathrm{HNO}_{3}$ solution.

\section{Influence of Sonication and Centrifugation Time}

In DMSPE, mass transfer takes place during the dispersive step. The effect of sonication time was evaluated in the range of 3-20 seconds. The results showed that the recovery of the analytes increased within the first 5 econds, and then the recovery of the analytes remained approximately constant after exceeding 5 seconds. Hence, a sonication time of 6 seconds was chosen for further study. In addition, the recovery of the analytes was also investigated as a function of centrifugation time at $5000 \mathrm{rpm}$. The experiments were performed in the range of 1-10 minutes. With increasing centrifugation time, the recovery of the analytes increased rapidly. Over 4 minutes, the recovery of the analytes was constant. Thus, 5 minutes was selected as the final centrifugation time.

\section{Effect of Desorption Time}

The effect of desorption time on the recovery of the analytes was investigated in the time range of 1-5 minutes by vortex. The experimental results showed that the analytes could be quantitatively recovered in the whole investigated time range, indicating a fast desorption dynamics. Therefore, 2 minutes was used as the desorption time.

\section{Selection of DLLME Conditions Effect of Sample $p H$}

For DLLME, the sample $\mathrm{pH}$ is a very important factor in the separation and concentration of the analytes since it affects the formation of the $\mathrm{Sb}$ (III)-APDC and $\mathrm{Sb}(\mathrm{V})$ APDC complex by using necessary hydrophobicity and their subsequent extraction. Therefore, the effect of sample $\mathrm{pH}$ on the signal intensities of the analytes was investigated in detail and the results are shown in Figure 2. As can be seen, the maximal signals of $\mathrm{Sb}(\mathrm{V})$ and $\mathrm{Sb}$ (III) were recorded in the $\mathrm{pH}$ range of $0-1.0$. It is worth noting that $\mathrm{Sb}(\mathrm{III})$ was also quantitatively determined in the $\mathrm{pH}$ range of 3.0-7.0. The reason for the facts mentioned above is that at the corresponding $\mathrm{pH}$ range, $\mathrm{Sb}(\mathrm{V})$ and $\mathrm{Sb}$ (III) could form the stable and hydrophobicity complexes with APDC. Based on these results, the upper aqueous phase $(\mathrm{pH}=5.0)$ containing $\mathrm{Sb}$ (III) and the desorp-

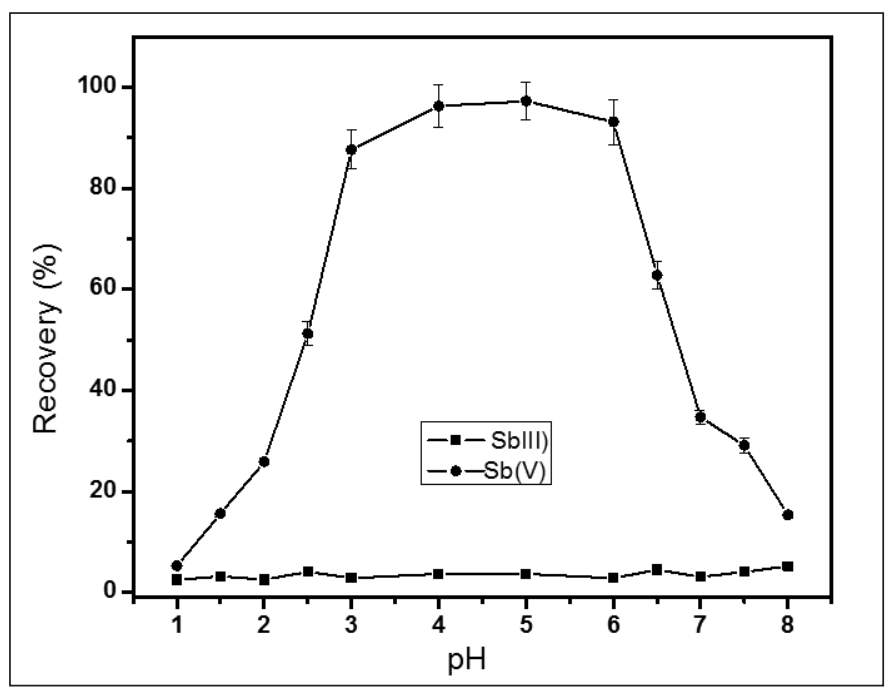

Fig. 1. Effect of $p H$ on the adsorption of analytes on TDNFs in DMSPE. Sb(III) and Sb(V):1.0 ng $\mathrm{mL}^{-1}$; sample volume: $5.0 \mathrm{~mL}$.

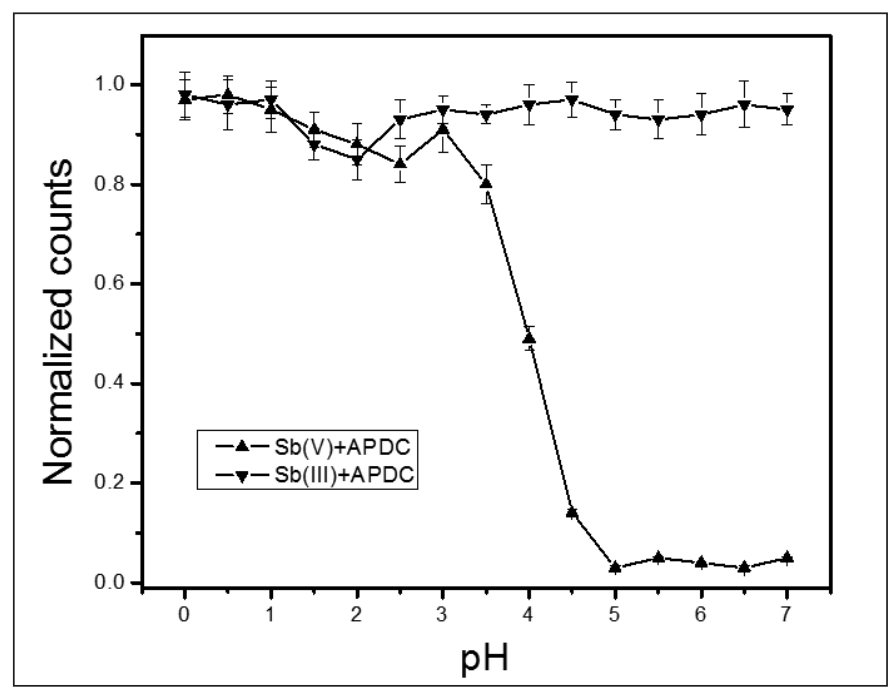

Fig. 2. Effect of sample $p H$ on signal intensity of analytes in DLLME. Sb(III) and $S b(V)$ : $1.0 \mathrm{ng} \mathrm{mL}^{-1}$; vaporization temperature: $2000^{\circ} \mathrm{C}$. 
tion solution $(\mathrm{pH}=0.5)$ containing $\mathrm{Sb}(\mathrm{V})$ from DMSPE were used for the direct determination of $\mathrm{Sb}$ (III) and $\mathrm{Sb}(\mathrm{V})$ by DLLME without any pre-oxidation or pre-reduction operation, respectively.

\section{Effect of Extraction Solvent and Its Volume}

In general, the extraction solvent should have low solubility in water and excellent extraction ability for the target analytes. In addition, it should have higher density than water to make the phase separation easy. For this purpose, chlorobenzene, 1,2-dichloroethane, and chloroform were investigated as the extraction solvents. The experimental results show that chloroform $\left(\mathrm{CHCl}_{3}\right)$ has better extraction efficiency among the tested solvents. Thus, $\mathrm{CHCl}_{3}$ was selected as the optimal extraction solvent.

The effect of extraction solvent volume on the extraction efficiency was also investigated in the range of $10-50 \mu \mathrm{L}$. The experimental results illustrate that the signal intensity of the analytes kept almost constant when the extraction solvent volume varied from 10 to 30 $\mu \mathrm{L}$. However, the signal intensity of the analytes decreased by further increasing the volume above $30 \mu \mathrm{L}$. In order to get a high enrichment factor, $15 \mu \mathrm{L}$ of $\mathrm{CHCl}_{3}$ was used as the extraction solvent in this work.

\section{Effect of Type and Volume of Dispersive Solvent}

In order to form the stable emulsion, the dispersive solvent in DLLME should be miscible with both water and extraction solvent. For this purpose, acetone, ethanol, and methanol were studied as the dispersive solvents. The experimental results show that the recovery of the analytes for acetone, ethanol, and methanol was 94.1\%, 96.3\%, and $97.5 \%$, respectively. The higher recovery was obtained using methanol, but ethanol has low toxicity and cost and was, therefore, selected as the disperser solvent.
In addition, the effect of ethanol volume on the signal intensity of the analytes was investigated in the range of $0.2-0.5 \mathrm{~mL}$. The experimental results show that a relatively high signal intensity and better reproducibility for the analytes were obtained with $0.2 \mathrm{~mL}$ ethanol as the dispersive solvent. Therefore, $0.2 \mathrm{~mL}$ of ethanol was selected as the optimum volume to achieve a stable cloudy solution.

\section{Influence of APDC Concentration}

The effect of APDC concentration on the signal intensity of the analytes was studied in the concentration range of $0.1 \times 10^{-2}-3.0 \times 10^{-2}$ mol L ${ }^{-1}$. The experimental results show that the signal intensity of the analytes increased with the increase of APDC concentration from 0.1 to $1.0 \times 10^{-2} \mathrm{~mol} \mathrm{~L}^{-1}$, and is then nearly constant when the concentration of APDC exceeds $1.0 \times 10^{-2} \mathrm{~mol} \mathrm{~L}^{-1}$. Taking into account that APDC could be consumed by the matrix in a real sample analysis, a relatively high concentration of $2.0 \times 10^{-2}$ mol L ${ }^{-1}$ APDC was used in subsequent work.

\section{Effect of Extraction and Centri- fugation Time}

The effect of extraction time was evaluated in the range of 5 seconds to 2 minutes. The experimental results show that the extraction time has no significant effect on extraction efficiency. This fact reveals that the interface area between the extraction solvent and the aqueous phase is extremely large due to the formation of a cloudy solution, resulting in the very fast mass transfer of the analytes from the aqueous phase to the extraction phase. Hence, the extraction time can be kept very short, which is the remarkable advantage of DLLME. Consequently, 5 seconds was selected for the extraction of the analytes. Besides, the effect of the centrifugation time was studied from 1 to 5 minutes at $5000 \mathrm{rpm}$. Satisfactory results were achieved within 3 to 5 minutes. Thus, 3 minutes was selected as the centrifugation time for this work.

\section{Effect of Potential Interference Ions}

The effect of various cations and anions commonly existing in biological samples on the extraction and determination of the analytes was examined based on the typical concentrations of these ions in real natural water samples. The tolerance limit of coexisting ions is defined as the largest amount making variation of less than $10 \%$ in the recovery of the analytes. The results show that $2000 \mathrm{mg} \mathrm{L}^{-1} \mathrm{Cl}^{-}$ and $\mathrm{NO}_{3}{ }^{-}, 1500 \mathrm{mg} \mathrm{L}^{-1} \mathrm{SO}_{4}{ }^{2-}, \mathrm{SiO}_{3}{ }^{2-}$ and $\mathrm{PO}_{4}^{3-}, 3000 \mathrm{mg} \mathrm{L}^{-1} \mathrm{~K}^{+}$and $\mathrm{Na}^{+}$, $2000 \mathrm{mg} \mathrm{L}^{-1} \mathrm{Ca}^{2+}$ and $\mathrm{Mg}^{2+}, 2.0 \mathrm{mg} \mathrm{L}^{-1}$ $\mathrm{Al}^{3+}$ and $\mathrm{Fe}^{3+}$ had no significant effect on the extraction and determination of the analytes.

\section{Optimization of ETV Conditions}

The ETV temperature program was optimized and selected in this work. A drying temperature of $100{ }^{\circ} \mathrm{C}$ and a drying time of $10 \mathrm{sec}$ onds were used for the removal of the water vapor during the drying step; a pyrolysis temperature of $200{ }^{\circ} \mathrm{C}$ and a pyrolysis time of 20 seconds were used for in situ removal of the extraction solvent from the graphite furnace. In addition, the effect of vaporization temperature on the signal intensity of the analytes was studied with a vaporization time of 4 seconds The experimental results show that with APDC as a chemical modifier, the maximum signal was obtained at $1900{ }^{\circ} \mathrm{C}$ for the analytes, and then kept constant with a further increase of vaporization temperature to $2200{ }^{\circ} \mathrm{C}$. Thus, a vaporization temperature of $2000{ }^{\circ} \mathrm{C}$ with a vaporization time of 4 seconds was used in this work.

\section{Analytical Performances}

Under the optimized conditions, some important parameters of this 
method, including precision, linear range of the calibration curve and the detection limits, were validated. The detection limits of Sb(III) and $\mathrm{Sb}(\mathrm{V})$, based on three times the standard deviation of the blank solution, were $0.025 \mathrm{pg} \mathrm{mL}^{-1}$ and $0.041 \mathrm{pg} \mathrm{mL}^{-1}$, respectively. The linear dynamic range of the calibration curve covered three orders of magnitude with a correlation coefficient better than 0.9932 . The relative standard deviation was $6.3 \%$ and $5.4 \%$ for $\mathrm{Sb}$ (III) and $\mathrm{Sb}(\mathrm{V})$ (c=1.0 ng mL $\mathrm{m}^{-1}, \mathrm{n}=9$ ), respectively.

\section{Sample Analysis}

Water samples (Wuhan, P.R. China), including wastewater, river water, and lake water, were collected in 50-mL polyethylene containers. They were filtered through a $0.45-\mu \mathrm{m}$ membrane filter and then stored in polyethylene bottles at $4^{\circ} \mathrm{C}$ for future use. This method was applied for the analysis of $\mathrm{Sb}$ (III) and $\mathrm{Sb}(\mathrm{V})$ in the water samples mentioned above. The results are listed in Table II. The recovery of the analytes was in the range of $94.0-105 \%$. In order to validate the accuracy of this method, a certified reference material GBW(E) 080545 water sample (Institute for Reference Materials of SEPA, Beijing, P.R. China) was analyzed, and the results were in good agreement with the certified value (Table III).

\section{CONCLUSION}

In conclusion, a new method was developed based on the dispersive micro-solid phase extraction (DMSPE) coupled with dispersive liquid-liquid microextraction (DLLME) and used for the determination of Sb species in environmen-

TABLE II

Analytical Results and Recoveries of Analytes in Environmental Water Sample

\begin{tabular}{llcccc}
\hline Sample & Species & $\begin{array}{c}\text { Content } \\
\left(\mathrm{ng} \mathrm{mL}^{-1}\right)\end{array}$ & $\begin{array}{c}\text { Added } \\
\left(\mathrm{ng} \mathrm{mL}^{-1}\right)\end{array}$ & $\begin{array}{c}\text { Found } \\
\left(\mathrm{ng} \mathrm{mL}^{-1}\right)\end{array}$ & $\begin{array}{c}\text { Recovery } \\
(\%)\end{array}$ \\
\hline Lake Water & $\mathrm{Sb}$ (III) & $0.46 \pm 0.04$ & 1.0 & $1.42 \pm 0.10$ & 96.0 \\
& $\mathrm{Sb}(\mathrm{V})$ & $1.64 \pm 0.13$ & 1.0 & $2.69 \pm 0.21$ & 105 \\
Wastewater & $\mathrm{Sb}$ (III) & $5.27 \pm 0.41$ & 2.0 & $7.22 \pm 0.35$ & 97.5 \\
& $\mathrm{Sb}(\mathrm{V})$ & $4.52 \pm 0.19$ & 2.0 & $6.40 \pm 0.29$ & 94.0 \\
River Water & $\mathrm{Sb}(\mathrm{III})$ & $0.69 \pm 0.04$ & 1.0 & $1.65 \pm 0.11$ & 96.0 \\
& $\mathrm{Sb}(\mathrm{V})$ & $2.14 \pm 0.11$ & 1.0 & $3.12 \pm 0.21$ & 98.0 \\
\hline
\end{tabular}

Mean value \pm standard deviation, $n=5$.

TABLE III

Analytical Results of Analytes in Certified Reference Material of Water Sample

\begin{tabular}{llcc}
\hline Sample & $\begin{array}{c}\text { Element } \\
\left(\mu \mathrm{g} \mathrm{mL}^{-1}\right)\end{array}$ & $\begin{array}{c}\text { Found }^{\mathrm{a}} \\
\left(\mu \mathrm{g} \mathrm{mL}^{-1}\right)\end{array}$ & $\begin{array}{c}\text { Certified } \\
(\%)\end{array}$ \\
\hline $\begin{array}{l}\text { Water Sample } \\
\text { GBW(E)080545 }\end{array}$ & Total Sb & $96.8 \pm 4.9$ & 100 \\
& $\mathrm{Sb}(\mathrm{III})$ & $5.7 \pm 0.4$ & - \\
& $\mathrm{Sb}(\mathrm{V})$ & $93.5 \pm 6.2$ & - \\
\hline
\end{tabular}

\footnotetext{
${ }^{a}$ Mean value \pm standard deviation, $n=5$.
}

tal water samples by ETV-ICP-MS. TDNFs were used as the adsorbent for the concentration and separation of the analytes. The upper aqueous phase and the elution solution from the DMSPE were used for further preconcentration and separation of $\mathrm{Sb}(\mathrm{III})$ and $\mathrm{Sb}(\mathrm{V})$ by DLLME, respectively. The extracts from DLLME were used for ETVICP-MS determination with APDC as a chemical modifier. This study may provide a potential technique for $\mathrm{Sb}$ speciation in real samples. In addition, this method has also the features of low detection limit, simple operation, good accuracy, and without use of a pre-oxidation or pre-reduction operation.

\section{ACKNOWLEDGMENT}

The authors are grateful for financial support from the Special Fund for Agro-scientific Research in the Public Interest (Project No. 201503135-22)

Received September 3, 2017.

\section{REFERENCES}

1. S. Chen, J. Li, J. Yan, D. Lu, and Y. He, At. Spectrosc. 37(6), 211 (2016).

2. Y. Hu, X. Hu, H. Liu, L. Huang, and R. Liu, At. Spectrosc. 35(2), 90 (2014).

3. S.L.C. Ferreiraa, W.N.L. dos Santosb, I.F. dos Santosa, M.M.S. Juniora, L.O.B. Silvaa, U.A. Barbosaa, F.A. de Santanaa, and A.F.S. Queirozd, Microchem. J. 114, 22 (2014).

4. H. Wu, X. Wang, B. Liu, Y. Liu, S. Li, J. Lu, J. Tian, W. Zhao, and Z. Yang, Spectrochim. Acta Part B 66(1), 74 (2011).

5. S.J. Majda, A. Sonja, and S. Trajce, Microchem. J. 99(1), 46(2011).

6. J. Plotka-Wasylka, N. Szczepanska, M. Guardia, and J. Namiesnik, TRAC Trends Anal. Chem. 77, 23 (2016).

7. J. Yan, S. Chen, J. Li, D. Lu, and Y. He, At. Spectrosc. 38(2), 42 (2017). 
8. R.F. Roi, P.V. Elena, and B.B. Pilar, At. Spectrosc. 37(6), 238 (2016).

9. H. Shirkhanloo, A. Khaligh, and H.Z Mousavi, Microchem. J. 124, 637 (2016).

10. M. Krawczyk and M. JeszkaSkowron, Microchem. J. 126, 296 (2016).

11. T. Khezeli and A. Daneshfar, TrAC Trends Anal. Chem. 89, 99 (2017).

12. Z. Es'haghi, G.R. Bardajee, and S. Azimi, Microchem. J. 127, 170 (2016).

13 M. Krawczyk and E. Stanisz, Talanta 161, 384 (2016)

14. J. Wanga, Z. Chenb, Z. Lic, and Y. Yanga, Food Chem. 204, 135 (2016).

15. A.C. Grijalba, L.B. Escudero, and R.G. Wuilloud, Spectrochim. Acta Part B 110, 118 (2015).

16. B. Feist, Food Chem. 209, 37 (2016).

17. S. Chen, J. Yan, J. Li, and D. Lu, At. Spectrosc. 38(4), 86 (2017).

18. J.S. Almeida, T.A. Anunciação, G.C. Brandão, A.F. Dantas, V.A. Lemos, and L.S.G. Teixeira, Spectrochim. Acta Part B 107, 159 (2015).

19. P. Liang and J. Cao, At. Spectrosc. 28(5), 178 (2007).

20. A. Jamshed, T. Mustafa, and K.T. Gul, At. Spectrosc. 38(2), 57 (2017).

21. X. Liu and Z. Fan, At. Spectrosc. 28(6), 215 (2007).

22 L. Wu, M. Hu, Z. Li, Y. Song, C. Yu, H. Zhang, A. Yu, Q. Ma, and Z. Wang, Food Chem. 192, 596 (2016).

23. S. Chen, S. Zhu, and D. Lu, At. Spectrosc. 35(1), 1 (2014).

24. M.A. Farajzadeh, S.M. Sorouraddin, and R.A. Mohammad, Microchim. Acta 181(9-10), 829 (2014).

25. H. Bin, H. Man, C. Beibei, and X. Linbo, Spectrochim. Acta Part B 86, 14 (2013).

26. M. Shamsipur, N. Yazdanfar, and M. Ghambarian, Food Chem. 204, 289 (2016).

27. S. Chen, J. Yan, J. Li, Y. Zhang, and D. Lu, At. Spectrosc. 38(1), 12 (2017).
28. T.J. Mohammad, S. Mohammad, and M. Mehdi, J. Chromatogr. A 1466, 50 (2016).

29. Y. Yamini, M. Faraji, and M. Adeli, Microchim. Acta 182(7-8), 1491(2015).

30. C. Diao, C. Li, X. Yang, A. Sun, and R. Liu, Microchim. Acta 183(3), 1261 (2016).

31. C. Inmaculada, P. Francisco, L. Isela, and B. Carlos, Anal. Chim. Acta 936, 12 (2016).

32. M.P. Jorge, G.S. Cristina, B.A. Carmen, L.M. Purificacion, M.L. Soledad, P.R. Dario, and B.B. Pilar, At. Spectrosc. 37(6), 218 (2016).

33. V. Padmasubashini and G. Chakrapani, At. Spectrosc. 37(6), 229 (2016).

34. S.R. Choudhury, D.C. Dutta, A. Karmakar, A. Das, and Y.K. Shami, At. Spectrosc. 37(2), 37 (2016).

35. S. Chen, J. Li, Y. He, and D. Lu, At. Spectrosc. 37(3), 96 (2016).

36. S. Chen, J. Li, D. Lu, and S. Zhu, At. Spectrosc. 37(1), 13 (2016).

37. Y. Li, W. Guo, Z. Wu, L. Jin, Y. Ke, Q. Guo, and S. Hu, Microchem. J. 126, 194 (2016).

38. Y. Peng, W. Guo, J. Zhang, Q. Guo, L. Jin, and S. Hu, Microchem. J. 124, 127 (2016).

39. Y. Zhang, X. Mao, J. Liu, M. Wang, Y. Qian, C. Gao, and Y. Qi, Spectrochim. Acta Part B 118, 119 (2016).

40. S. Chen, J. Li, D. Lu, and S. Zhu, At. Spectrosc. 37(1), 13 (2016).

41. S. Chen, X. Cheng, Y. He, S. Zhu, and D. Lu, Microchim. Acta 180(15-16), 1479 (2013).

42. S. Chen, D. Lu, and S. Zhu, At. Specrtrosc. 33(1), 9 (2012).

43. L. Ying, $\mathrm{H}$. Man, C. Beibei, and $\mathrm{H}$. Bin, Talanta 142, 213 (2015).

44. Y. He, M. He, B. Chen, and B. Hu, Spectrochim. Acta Part B 122, 94 (2016).

45. S. Chen, S. Zhu, and D. Lu, At. Spectrosc. 36(3), 128 (2015).

46. D. Vu, Z. Li, H. Zhang, W. Wang, Z. Wang, X. Xu, B. Dong, and C. Wang, J. colloid. Interf. Sci. 367, 429 (2012).

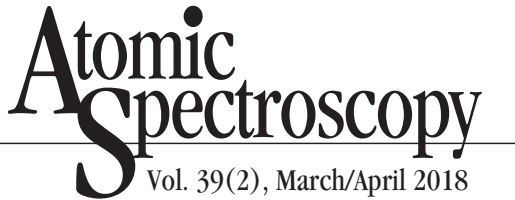

47. A. Maqieira, H. A. M. Elmahadi, and R. Puchades, Anal. Chem. 66, 3632 (1994). 